\title{
EL ACONTECER DEL PENSAMIENTO DE CRISTO ${ }^{1}$
}

\section{THE OCCURRENCE OF THE THOUGHT OF CHRIST}

\author{
AGOSTINO MOLTENI* \\ Dr. en Teología Dogmática \\ Universidad Católica de la Santísima Concepción, Chile \\ DAVIS SOLÍS-NOVA** \\ Dr. en Filosofía \\ Universidad Católica de la Santísima Concepción, Chile
}

\begin{abstract}
Artículo recibido el 29 de junio de 202I; aceptado el 25 de diciembre de $202 \mathrm{I}$.
*amolteni@ucsc.cl

https://orcid.org/oOOO-OOOI-5392-OI83

**dsolis@ucsc.cl

https://orcid.org/oooo-0003-2462-8436
\end{abstract}

Cómo citar este artículo:

MOLTENI, A. y SOLÍS, D. "El acontecer del pensamiento de Cristo" en Palabra y Razón. Revista de Filosofía, Teología y Ciencias de la Religión. No 20 DICIEMBRE 202I, pp. 74-97 https://doi. org/10.29035/pyr.20.74

I El presente artículo es producto de un proyecto externo de investigación integrado en el acuerdo de colaboración en investigación entre la Universidad Católica de la Santísima Concepción, Concepción, Chile y la Associazione Piccola Via Onlus, Roma, Italia, titulado "El pensamientocuerpo de Cristo" de mayo de 202I. 


\title{
RESUMEN
}

San Pablo afirma que la fe consiste en tener "el pensamiento de Cristo" (I Co 2, I6). La afirmación paulina implica, ante todo, la afirmación del "pensamiento de (genitivo subjetivo) Cristo". En este estudio se quiere mostrar de modo sintético en qué consiste el acontecer del pensamiento de Cristo. En primer lugar, se indagará cuál es su método de pensamiento. Se mostrará que es com-puesto con el Padre; entre el Logos y el pensamiento del hombre judío que es Jesús; con los hombres. En un sintético apéndice se inferirá lo que esto significa para reconocer en qué consiste el cuerpo de Cristo. En segundo lugar, se mostrarán las dimensiones de su pensamiento: la autoridad y la imputabilidad. En las conclusiones se recopilarán algunos datos y ofreceremos, además, sugerencias que pueden servir para solucionar algunas cuestiones referentes al modo de entender a Cristo.

Palabras claves: Cristo / pensamiento / acontecer / autoridad / imputabilidad

\begin{abstract}
Saint Paul affirms that faith consists in having "the thought of Christ" (I Cor 2:I6). The Pauline affirmation implies, first of all, the affirmation of the "thought of (subjective genitive) Christ". In this study we want to show in a synthetic way what the occurrence of the thought of Christ consists of. In the first place, it will be investigated its method of thought. It will be shown that he is compounded with the Father; between the Logos and the thought of the Jewish man who is Jesus with men. In a synthetic appendix we will infer what this means to recognize what the body of Christ consists of. Second, the dimensions of his thinking will be shown: authority and accountability. In the conclusions, some data will be collected and we will also offer suggestions that can be used to solve some questions regarding the way of understanding Christ.
\end{abstract}

Keywords: Christ / thought / happening / authority / imputability 


\section{Introducción}

San Pablo afirma que la fe consiste en tener "el pensamiento de Cristo" (I Co 2, I6). Esto no significa solo reconocer lo que hace posible la fe razonable del cristiano. La afirmación paulina implica, ante todo, la afirmación del "pensamiento de (genitivo subjetivo) Cristo", es decir, la identificación de un sujeto, Cristo, capaz de un pensamiento que tiene una lógica propia.

La importancia de la retoma de esta temática se debe a dos factores. Por un lado, nos parece que esta dimensión no ha recibido la atención suficiente en la historia de la fe cristiana, exceptuando de esto la elaboración de los primeros dogmas en contra del monofisismo que negaba la razón humana de $\mathrm{Cristo}^{2}$. Por lo que se refiere al casi nulo desarrollo de la reflexión en los Padres y en la Escolástica acerca de la expresión de san Pablo referida al pensamiento propio de Cristo, es significativo el silencio, entre otros, de san Ireneo, san Agustín y santo Tomás de Aquino, en cuyas obras no hemos encontrado un desarrollo de esta temática que nos parece fundamental ${ }^{3}$. Por lo que sabemos, también la reflexión teológica moderna y actual no se ha detenido sobre este punto 4 .

Por otro lado, hay distintas causas que, de alguna manera, han mistificado y removido el pensamiento propio de Cristo. Entre otras, a modo de esbozo, señalamos tres que nos parecen significativas.

La primera causa puede ser la discutida helenización del

\footnotetext{
2 Recordamos, entre otras, algunas afirmaciones fundamentales: "Anatematizamos a aquellos que dicen que el Verbo de Dios estuvo en la carne humana en lugar del alma racional e inteligente del hombre": E. DENZINGER, El magisterio de la Iglesia. Definiciones y declaraciones de la Iglesia en materia de fe y de costumbres. Herder: Barcelona, 1963, n. 65; "Habiendo unido consigo el Verbo, según hipóstasis o persona, la carne animada de alma racional, se hizo hombre de modo inefable e incomprensible". E. DENZINGER. El magisterio... n. III. "Cristo es verdaderamente hombre de alma racional y de cuerpo". E. DENZINGER El magisterio... n. I48. En la iconografía de la Iglesia primitiva es conocida la imagen de Cristo filósofo en las catacumbas romanas de Domitila.

3 Está claro que no desconocemos que los Padres hablaron de la doctrina de Cristo como de la verdadera filosofía-gnosis-conocimiento. Sin embargo, no se ha insistido lo suficiente en que Cristo debió pensar el método y contenido de su encarnación y redención. Cristo no es el simple portador de una doctrina, sino el elaborador de un pensamiento.

4 En el ámbito exegético, cf.: G. MOLETTA. Noi abbiamo il pensiero di Cristo. Meditazioni sulla Prima lettera ai Corinzi. Messaggero: Padova, 20I7; para una posible y necesaria relación entre el pensamiento de Cristo y la pastoral cristiana, cf.: A. SCOLA. Educarsi al pensiero di Cristo. Lettera pastorale 20I5-20I7. Centro Ambrosiano: Milano, 20I5; para la importancia del pensamiento de Cristo en relación a la vida cristiana y sacerdotal, cf.: F. MANZI. Il pensiero di Cristo, i segni dello Spirito e il desiderio di vita. Itaca: Castel Bolognese, 202I.
} 
pensamiento de Cristo producida en la reflexión teológica5. Esta inclinación teológica ha llevado a pensar que para entender a Cristo haría falta recurrir al pensamiento racional griego, externo y distinto al pensamiento propio de Cristo $^{6}$. Esta helenización, si bien no ha contagiado los contenidos y dogmas $\mathrm{de}^{\mathrm{fe}^{7}}$, se puede decir que ha relegado al pensamiento de Cristo que, como veremos, no solo tiene su origen y acontecer en el ámbito intratrinitario, sino también en el hebreo.

La segunda causa puede ser la reducción religiosa que se ha intentado ejercer sobre el acontecer del pensamiento de Cristo. El Dios de Jesús sería, según esta lectura, el Dios genérico-indistinto-ecuménico de las religiones, relegando el hecho de que, como veremos, Jesús afirma y revela que Dios es Dios porque es Padre (no el contrario) y que su Padre es, lejos de cualquier tentación de marcionismo, el de la Alianza con Abraham.

La tercera es que el pensamiento teológico, en variadas ocasiones, ha sido contagiado por un subterráneo docetismo. Generalmente, se suele considerar el docetismo como la herejía que afirma que el cuerpo de Cristo es solo aparente. En realidad, pensamos que la herejía del docetismo no consiste en negar el organismo físico de Cristo, sino en considerarlo solo como un cuerpo natural y no como un cuerpo sobrenatural, bio-lógico y meta-físico. Por lo tanto, el error de los docetas es descartar el hecho de que el cuerpo de Cristo es el cuerpo de un pensamiento ${ }^{8}$.

Ahora bien, dada esta situación de olvido y, por otro lado, de mistificación, la intención de este estudio es mostrar, de modo necesariamente sintético, que es posible reconocer la naturaleza del

\footnotetext{
5 No podemos aquí entrar a detallar esta vexata quaestio.

6 La Carta de Bernabé (XIX, 7) ya había avisado a los cristianos "no ser dobles ni de pensamiento ni de lengua”: en D. RUÍZ BUENO (Ed.). Padres apostólicos. BAC: Madrid, 1993, p. 807. Para una diferenciación entre el pensamiento hebreo de Cristo y el griego-filosófico, cf.: A. MOLTENI. "Pensamiento de Cristo e idealismo griego: para una relectura de Laberthonnière", Veritas. 35 (2016), pp. I87-215. Disponible en: http://dx.doi.org/I0.4067/So718-92732016000200009.

7 Los primeros Concilios de la Iglesia han combatido victoriosamente contra la helenización del acontecimiento cristiano. Véase GRILLMEIER. Cristo en la tradición cristiana. Desde el tiempo apostólico hasta el Concilio de Calcedonia. Sígueme: Salamanca, 1997, p. 449. Se ha sostenido que "el pensamiento helenista no llegó nunca a imponerse por completo, pues estuvo siempre sometido a la crítica cristiana": B. STUDER, Dios salvador en los Padres de la Iglesia. Secretariado Trinitario: Salamanca, 1992, p. 39. Véase también: L. SCHEFFCZYK. "La helenizacion del cristianismo: reflexiones de actualidad in Homenaje a Federico Stegmüller" en Revista española de Teología. 4I/I63 (I98I), pp. 469-48I.

8 Según san Agustín, los apolinaristas, "careciendo estos de razón, quitaron a Cristo la razón", su pensamiento de hombre: AGUSTÍN. Commento al Vangelo di Giovanni, XLVII, 9. Città Nuova: Roma, 2005, p. 753.
} 
pensamiento de Cristo solo en su acontecer, que no está ya hecho, presupuesto. Esto se verá en el método con el que Cristo pensó, ya sea intrinitariamente como en la continuación terrenal de este pensamiento que se pro-pone a los hombres. Este acontecer del pensamiento se co-instituye en Cristo con las dos dimensiones de autoridad y de imputabilidad.

Notamos de antemano que en el breve espacio de este artículo solo podremos hacer unas breves alusiones a la lógica con que Cristo ha cumplido su encarnación y la redención de los hombres. Por otro lado, señalamos que, para el estudio de esta temática, los textos del Nuevo Testamento que citaremos ${ }^{9}$ serán leídos desde la fe cristiana con la intención de introducirnos en el pensamiento revelado por y en Cristo, sin pretensión exegética estricta ${ }^{\mathrm{IO}}$.

En este sentido, como método, hemos intentado pensar desde dentro del encuentro con el pensamiento de Cristo, así como lo hemos heredado por la fe cristiana de la Tradición eclesial ${ }^{\mathrm{II}}$.

\section{Un método de pensamiento}

La quaestio del acontecer del pensamiento de Cristo, de antemano, obliga a pensar la lógica, mejor dicho, el método con el que Cristo ha pensado. Si él ha dicho de sí mismo: "Yo soy el camino" (Jn I4, 6) I2 $^{12}$ significa que se ha identificado con el método con el cual se puede pensar a Dios. En él, el método y el contenido de la revelación del Padre coinciden: "El que me ha visto a mí, ha visto al Padre” (Jn I4, 9). Estas afirmaciones implican que, muchos siglos antes de Descartes, Cristo ya se había planteado la cuestión del método, de cómo pensar, de cómo bien conduire sa raison-pensamiento.

9 Utilizamos para las citas bíblicas: Biblia de Jerusalén. Desclée de Brouwer: Bilbao, 1975. En las citas, donde lo estimamos oportuno y entre paréntesis cuadrados, ponemos nuestra posible lectura. Se señalará si traducimos de otra forma los textos bíblicos.

Io Véase lo que escribe H. SCHLIER: "Resulta claro que el teólogo del Nuevo Testamento no necesita solo el método histórico-filológico, sino también uno teológico. [...] Este introducirse [en el Nuevo Testamento] se realiza en la fe. [...] Quien interprete [a Cristo] solo históricofilológicamente, pero no se introduzca en su pensamiento nunca se encontrará con la realidad que [Cristo] ha descubierto, ni vivirá de ella": citado en J. RATZINGER. Teología e historia. Notas sobre el dinamismo histórico de la fe. Sígueme: Salamanca, 1972, pp. I24-I25. Cursivas nuestras.

II Nuestro método sigue la recomendación de Gabriel Marcel cuando afirma que en la experiencia de un encuentro (en nuestro caso con el pensamiento de Cristo) "no puedo situarme realmente fuera de él ni frente a él; estoy comprometido en este encuentro, dependo de él, le soy, en cierto sentido, interior. (...) Él ha actuado en mí como principio interior a mí mismo": G. MARCEL. Aproximación al misterio del ser. Posición y aproximaciones concretas al misterio ontológico. Madrid: Encuentro, 1987, pp. 42-43. Cursivas nuestras.

I2 Véase también lo que escribe I. DE LA POTTERIE. La verdad de Jesús. Estudios de cristología joanea. BAC: Madrid, I979, pp. I07-I44. 
Ahora bien, ¿cuál es el método del acontecer del pensamiento de Cristo?, ¿cómo ha bien conducido su razón-pensamiento?

\section{I.I. Un pensamiento que acontece, pues es genitus non factus}

Se podría decir que su primera regla de método ha sido la no remoción del pensamiento de su Padre, o sea, que no se ha separado de él: no ha fallado al pensamiento de su Padre, no ha sido parricida, es más, ha compuesto $^{13}$, complaciéndose, su pensamiento con el Padre. Siguiendo en eso al pensamiento hebreo de la antigua Alianza, su pensamiento no ha sido compuesto con un Dios indistinto sino con su Padre. En el evangelio de san Juan, Cristo se refiere siempre al Padre y si este llega a merecer el nombre de Dios es porque, primeramente, ha obrado como Padre, como su Padre (Jn 5, I7).

Ahora bien, Cristo ha pensado com-poniendo su lógica, la de cómo encarnarse y redimir a los hombres, con el Padre. El pensamiento, según una buena lógica, o acontece en una relación o no es pensamiento, mejor dicho, termina siendo simplemente un sistema, una teoría inmovilizada. Estimamos que esto es explícito en Cristo. En el prólogo de san Juan se dice que en el principio el Verbo estaba vuelto hacia el Padre (Jn I, I I ${ }^{14}$, com-poniendo su pensamiento con el Padre. En este sentido, pensamos que no se puede traducir este versículo como si el Hijo, el Logos, estuviera simplemente junto, al lado de Dios, del Padre, como un ente estático. Al contrario, hay que pensar que Cristo estaba vuelto con su pensamiento hacia el Padre, pues estaba "en el seno del Padre" (Jn I, I8)"

Leclercq ha hecho notar de modo pertinente que Cristo ha continuado en la tierra la relación que vivía intratrinitariamente ${ }^{16}$. Son conocidas las afirmaciones de Cristo en este sentido y, sin embargo, si se leen como el método con que él ha pensado, pueden adquirir un sentido renovado. De hecho, a menudo, Cristo señala que el método con que piensa es com-puesto con su Padre: "El Hijo no puede hacer nada por su

I3 En este artículo preferimos escribir el término "compuesto" con guion para subrayar y enfatizar más el acontecer del pensamiento de Cristo que es acto puesto y com-puesto con el Padre. Esto vale también cuando, para otros términos, hemos preferido utilizar el guion.

I4 Esta es la lectura de I. De la Potterie citada por R. BROWN, El evangelio según Juan I-XII. Cristiandad: Madrid, 1999, p. 195; véase también J. LECLERCQ. Consideraciones monásticas sobre Cristo. Desclée de Brouwer : Bilbao, 1999, p. 35.

I5 Para san AGUSTÍN "estar en el seno del Padre" significa estar "en el secreto del Padre. [...] Aquel que conoce al Padre en su íntimo secreto, ha venido a revelarlo a los hombres": Commento al Vangelo di Giovanni..., III, I7, p. I22.

I6 "Vino a nosotros para continuar aquí lo que hacía desde toda la eternidad". J. LECLERCQ, Consideraciones monásticas sobre Cristo..., p. 35. 
cuenta, sino lo que ve hacer al Padre; lo que hace él, eso también lo hace igualmente el Hijo" (Jn 5, I9); "Yo no puedo hacer nada por mí cuenta: juzgo [pienso] según lo que oigo; y mi juicio [pensamiento] es justo porque no busco mi voluntad, sino la voluntad del que me ha enviado" (Jn 5, 30). Lo que significa que el método y contenido del pensamiento de Cristo es justo y sano porque piensa según el pensamiento del Padre: "He bajado del cielo, no para hacer mi voluntad, sino la voluntad del que me ha enviado" (Jn 6, 38). Se podría decir que su ser es propiamente esta relación de pensamiento com-puesta con el Padre: "Yo estoy en mi Padre" (Jn I4, 20) $)^{17}$; "Yo y el Padre somos uno" (Jn IO, 30).

En este sentido, es interesante notar la afirmación de Cristo cuando dice: "Salí del Padre y he venido al mundo; ahora dejo otra vez el mundo y voy al Padre" (Jn I6, 28). Cristo sale del Padre y, al mismo tiempo, permanece vuelto hacia el Padre. Por ello, cuando envía a sus apóstoles, les pedirá permanecer en él (Mc 3, I4) como él permanece en el Padre, "en su amor" (Jn I5, IO). A este propósito, para la fe cristiana, permanecer en él significa permanecer en su pensamiento com-puesto con el Padre.

Ahora bien, el pensamiento de Cristo no está ya hecho ni se lo debe dar por pre-supuesto porque, propiamente, acontece en la relación con el Padre, com-poniendo su pensamiento con este, más bien, remontando ${ }^{18}$ el pensamiento del Padre: "Nadie ha subido [asciende] al cielo sino el que bajó del cielo, el Hijo del hombre" (Jn 3, I3-I4). Sobre este punto se puede decir que la Ascensión no está solo al final de la vida de Cristo, sino que es el movimiento continuo de su pensamiento que asciende el pensamiento del Padre, que lo remonta, que lo piensa con inicios continuos. Como hemos señalado, una relación no está ya-hecha, sino que acontece con inicios siempre nuevos, imprevistos e imprevisibles. Por tanto, el método o, dicho de otra forma, la condición de posibilidad del pensamiento de Cristo es el acontecer de la relación de pensamiento con su Padre ${ }^{19}$.

Es más, esta relación, por ser propiamente una generatio, no es de ningún modo causada como la relación del esclavo que obedece ciegamente a su amo, sino que es la de Hijo que permanece en el seno

I7 La Vulgata dice de modo más claro: Ego sum in Patre meo.

I8 Usamos el término "remontada" tomándolo de Charles Péguy, de su reflexión cristológica. En el pensamiento de Péguy "el término fundamental es remonter": H. U. VON BALTHASAR. Gloria. Estilos laicales. Encuentro: Madrid, 1986, p. 469.

I9 Para IRENEO, "el Verbo de Dios al hacerse carne [...] tiene la primacía sobre todo el cielo: [es] primogénito del pensamiento del Padre". Demostración de la predicación apostólica, 39. Ciudad Nueva: Madrid, I992, p. I4I. 
del Padre eternamente: "El esclavo no se queda en casa para siempre; mientras el hijo se queda para siempre" (Jn 8, 35). Esto significa que el pensamiento de Cristo no acontece de modo sumiso, ni según un dispositivo lógico divino ya pre-establecido. Si así fuera, la lógica con que piensa sería patológica, pues sería causada por el Padre y su pensamiento sería solo un mero efecto. Cristo, en este caso, sería solo un sujeto religioso causado y sometido a un Dios religiosamente sagrado e inimputable del que no sabría ni qué piensa ni qué quiere.

Sin embargo, uno de los más esplendorosos dogmas, el del Concilio de Nicea de 325, afirma que Cristo es genitus non factus $^{20}$, engendrado no creado. Este dogma proclama que Cristo no es, como quería el arrianismo, una mera criatura natural-biológica, un Deus sive natura. Esto significa que el ser del Hijo es meta-físico, sobre-natural, el de un sujeto jurídico en cuanto es engendrado por y en la alianza con su Padre. Su ser no es causado cual mero efecto cosmológico por una Causa Primera, sino que la generación de su ser es la de las razones jurídicas de una filiación. De hecho, el Padre no genera un efecto, sino un Hijo y un heredero. Su ser Hijo, divino, no es antecedente a su relación con el Padre, sino que acontece en ella. En relación a nuestra temática, esto significa que el Hijo no es hijo de una manera predeterminada, sino en la medida en que piensa y asciende el pensamiento del Padre. Por otro lado, el Padre es tal no de una vez para siempre, sino en cuanto se co-instituye en, con y por el pensamiento del $\mathrm{Hijo}^{21}$. El ser y pensamiento intratrinitario de Cristo, por tanto, es el de un esse ut actus, es decir, el de un ser que se co-instituye en el acto de relación con su Padre y el Espíritu Santo.

\section{I.2. El Logos y su pensamiento de hombre}

Ahora bien, intratrinitariamente el Hijo desea hacerse hombre y pide al Padre un cuerpo. Una vez que es puesto en una carne humana por el Padre ("Me has formado un cuerpo": Hb Io, 5; en este sentido habría que conservar la forma pasiva del factum est de Jn I, I4: "Ha sido hecho carne") y acepta libremente su "puesta en la carne" (mise en chair) ${ }^{22}$, continúa este esse ut actus intratrinitario. Es más, esta co-institución relacional intratrinitaria es la condición de posibilidad para que Cristo

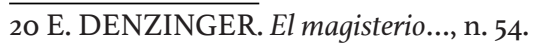

2I No se quiere aquí indicar una sumisión del Padre al Hijo, sino, como escribe J. GALOT, "el Padre es el Padre en virtud de su relación al Hijo": "Valeur de la notion de personne dans l'expression du mystère du Christ". Gregorianum. 55/I (I974), p. 95. Disponible en: https://www. jstor.org/stable/23575214.

22 Usamos aquí la expresión de C. PÉGUY. Victor-Marie, comte Hugo, en Euvres en prose complètes III. Gallimard: Paris, 1992, p. 233. 
pueda cumplir la unidad-relación con la naturaleza humana que él asume y asciende. Esto significa que el Logos no se impone de modo vertical (gnóstico-monofisita), autoritario al pensamiento del hombreJesús causándolo, sustituyéndolo o eliminándolo ${ }^{23}$. Las dos naturalezas racionales de Cristo se com-ponen, trabajan juntas, colaboran entre sí teniendo como sujeto una Persona, la del Hijo, que impide que estas dos naturalezas estén disociadas entre ellas con dos historias, pensamientos, actos y mundos separados y contradictorios ${ }^{24}$. Al contrario, por la persona del Logos, se cumple este admirabile commercium por el cual el Hijo encuentra conveniente para sí su relación con la naturaleza humana ${ }^{25}$.

Esto implica que, puesto que el hombre es a imagen y semejanza de Dios (de las relaciones intratrinitarias) su naturaleza no es meramente natural sino meta-física, sobre-natural (a imagen y semejanza de Dios). De este modo, el Logos, haciéndose hombre, viene entre "los suyos" (Jn I, II), no viene a habitar en algo extraño a su naturaleza meta-física, sobrenatural ${ }^{26}$. Para él, no hay razones para una posible contradicción entre las dos naturalezas, pues no están ya hechas y, por obra de la única persona del Logos, viven un movimiento continuo de co-laboración y co-operación recíproca, un admirabile commercium y una communicatio idiomata con-veniente.

La encarnación y redención son la demonstración in actu exercito del trabajo com-puesto entre el Logos y el pensamiento del hombre que es Jesús. De hecho, el "yo" de Cristo es co-instituido, com-puesto ${ }^{27}$ en cuanto asciende y remonta libremente tanto el pensamiento del Padre como la alianza con los hombres (como veremos). Su "yo" es propiamente trabajo ("Mi Padre trabaja hasta ahora y yo también trabajo": Jn 5, I7), colaboración con el pensamiento del Padre.

23 El Concilio de Éfeso ha declarado: "Pues, no decimos que la naturaleza del Verbo, transformada, se hizo carne; pero tampoco que se trasmutó en el hombre entero, compuesto de alma y cuerpo; sino, más bien, que habiendo unido consigo el Verbo, según hipóstasis o persona, la carne animada de alma racional, se hizo hombre". E. DENZINGER. El magisterio..., n.III.

24 Es nuestra lectura del dogma cristológico de Calcedonia. E. DENZINGER. El magisterio..., n. I48.

25 El conocido axioma cristiano: Gratia perficit naturam, non destruit, encuentra en el trabajo de co-laboración entre el Logos y la razón del hombre Jesús, su fundamento. La misma redención sigue esta lógica.

26 Se ha escrito del hombre entendido como único sujeto adecuado para la encarnación : "Tan elevada Economía no se realizó a través de creaturas ajenas, sino propias. [...] Porque el Padre no era tan injusto como para desear lo ajeno (...) sino que dirigió la propia acción creadora a la salvación del hombre". IRENEO. Contra los herejes. Conferencia del Episcopado Mexicano: México, 2000, p. 515. Cursivas nuestras.

27 El Constantinopolitano II declara que la unión del Verbo con la carne es "según composición, es decir, según hipóstasis". E. DENZINGER. El magisterio..., n. 216. 


\section{I.3. El Logos y el pensamiento humano-hebreo de Jesús}

Hemos señalado que, contra cualquier monofisismo docetista, se debe afirmar que el Logos no sustituye a la razón del hombre Jesús, so pena de una negación de que él sea vere homo.

En este punto, es importante señalar que el pensamiento del hombre Jesús es hebreo. En el ámbito cristiano, jamás se debe dar por superada la tentación hereje de Marción, la de separar el Antiguo y el Nuevo Testamento, mejor dicho, la de separar a Cristo del pensamiento que el Padre había compuesto en la Alianza con Abraham e Israel. Por lo mismo, ha afirmado: "No penséis que he venido a abolir la Ley y los Profetas, sino a dar cumplimiento" (Mt 5, I7).

De hecho, en sus treinta y tres años, es desde dentro de la alianza con el Dios de Abraham que él continua terrenalmente la alianza intratrinitaria. Las mismas Escrituras "dan testimonio" de él $(\mathrm{Jn} 5,39)$, pues ha mostrado, aunque afirme existir antes de Abraham (Jn 8, 58) ${ }^{28}$, ser capaz, como hombre judío, de remontar el pensamiento del Padre de la Alianza ${ }^{29}$. Por eso Abraham se alegró viendo el día de Cristo $\left.(J n) 8,58\right)^{30}$.

Esto significa que Cristo se ha comprendido a sí mismo no solo en relación con el Padre y el Espíritu Santo ${ }^{31}$, sino con la raza de su pensamiento hebreo, el de la Primera Alianza, de la cual se nutre ${ }^{32}$. Decir que "Jesús se comprende y comprende su misión a través de la Escritura"33, significa que aprende de este pensamiento del cual se nutre quién es el Dios de Israel, el de los Padres. Si desde la eternidad Cristo se sabe Hijo, en cuanto se hace hombre aprende que su filiación propia es la de ser Hijo del Padre de la Alianza con Israel.

Por tanto, no se puede reconocer el acontecer del pensamiento de

\footnotetext{
28 Cristo "se había hecho descendencia de Abrahán y, para que Abrahán fuese hecho, antes de Abrahán existía él mismo” AGUSTÍN. Commento al Vangelo di Giovanni..., XLIII, I7, p. 706.

29 Este arraigo de Jesús en la raza hebrea es uno de los elementos reclamados justamente por la denominada Third quest. No podemos aquí señalar la múltiple producción crítica sobre este tema, ni discutirla.

30 San Agustín afirma que "aquellos que rechazan la carne de Cristo, rechazan la acción de Abraham". AGUSTÍN. Commento al Vangelo di Giovanni..., XLIII, I6, p. 705.

3I No podemos detallar aquí la decisiva co-operación del Espíritu en todos los actos de la vida terrenal de Cristo.

32 Está claro que entendemos el término raza no en sentido biológico, físico-natural.

33 Usamos aquí la bella expresión de J. LECLERCQ, Consideraciones monásticas sobre Cristo..., p. 37. Se ha escrito también que Jesús "se ha comprendido a sí mismo desde la lectura del Antiguo Testamento": O. GONZÁLEZ DE CARDEDAL. Cristología. BAC: Madrid, 2005, p. 72.
} 
Cristo sin su inserción espacio-temporal en la historia, es decir, sin su pertenencia a una raza de pensamiento, la hebrea. En el acontecimiento del pensamiento hebreo de Jesús está, a nuestro parecer, una de las pruebas más evidentes de su historicidad. Jesús es un judío que asciende y remonta la herencia de esta alianza de pensamiento ${ }^{34}$. Claro está, la hereda con el beneficio de inventario de lo que Israel había transgredido respecto a esta alianza.

Una sana cristo-lógica debería, por tanto, ser la "cristología de Jesús de Nazaret, la cual, tomada en su intención más profunda, expresa la singularidad de Jesús"35. Singularidad que es fruto de su singular relación de pensamiento con el Padre que es el de la Primera Alianza. En este sentido, como se ha escrito de modo muy significativo, para comprender el acontecer del pensamiento de Cristo, huyendo de cualquier gnosticismo y docetismo, hay que reconocer que "donde falla esta mediación [de Israel, de la raza de pensamiento hebrea], Jesús no brota y asciende de la matriz de su raza, sino que desciende gnósticamente, como cayendo de los cielos" ${ }^{36}$.

\section{I.4. Un pensamiento com-puesto con los hombres}

Además de la remontada del pensamiento del Padre que es el de la primera Alianza, el pensamiento de Jesús acontece en la relación con los hombres.

Ante todo, porque aprende de ellos ${ }^{37}$. En los treinta años en Nazaret,

\footnotetext{
34 Se ha escrito: "Jesús tenía un país local y temporal. Él de ningún modo ha venido a la tierra por azar, sino que partiendo de Judea; ha venido en el tiempo y en la eternidad partiendo de un cierto punto del tiempo": C. PÉGUY, Dialogue de l'histoire et l'âme païenne, en Euvres en prose complètes III..., p. II7I. Haber nacido en un espacio y tiempo determinados, no es una limitación para Jesús, sino una riqueza. Se ha afirmado justamente que "es a través de estos límites históricos, que él alcanzará a todo hombre: no superando estos límites, sino en ellos. No se trata de negar en Jesús al judío, al galileo". C. DUQUOC. Cristología. Ensayo dogmático sobre Jesús de Nazaret el Mesías. Sígueme: Salamanca, 1974, p. 45.

35 COMISIÓN TEOLÓGICA INTERNACIONAL, "Teología-cristología-antropología", I, BI, 3. Disponible en: https://www.vatican.va/roman curia/congregations/cfaith/cti documents/rc cti_I982 teologia-cristologia-antropologia sp.htmlen. [consulta: 2020-03-II].

36 H. U. VON BALTHASAR. Gloria. Estilos laicales..., p. 433. El versículo de Is 45, 8 (según la Vulgata): "Aperiatur terra, et germinet Salvatorem", puede ser leído como este trabajo de ascensiónremontada cumplida por Cristo desde el pensamiento humano-hebreo. Véase por este tema: A. MOLTENI. "La encarnación vista desde lo pagano. La lectura de Charles Péguy de Booz endormi de Victor Hugo". Franciscanum. 62/174 (2020), pp. I-26. Disponible en: https://doi. org/I0.21500/0I20I468.4883.

37 Para Tomás de Aquino "hay que reconocer en Cristo la ciencia adquirida. Ella es una ciencia al modo humano connatural al hombre". S. Th. III, q. 9, a. 4. Suma de Teología. BAC: Madrid, I994, p. I40. Sin embargo, en la cuestión: "Si Cristo aprendió algo de los hombres", su respuesta será: "No fue conveniente a su dignidad [de Cristo] ser instruido por alguno de los hombres". S. Th. III, q.
} 
aprende terrenalmente a ser hijo obediente al Padre en la relación con María y José (con la salvedad de reivindicar los derechos de su Padre: Lc 2, 49; cf. también Mt I2, 48). Los dos versículos de Lc 2, 40 y 52, deberían ser leídos también como su crecimiento y fortalecimiento en la experiencia de ser hombre. De hecho, aprende el trabajo manual de carpintero de su padre putativo y las leyes económicas y cívicas terrenales. Además, en su ministerio público, se podría decir que para Jesús y su pensamiento vale el refrán: "Dime con quién andas y te diré quién eres". En este sentido, se ha escrito que, puesto que "el hombre bíblico se comprende más como relación que como realidad (...) podemos descubrir su identidad a partir de las relaciones que instaura" ${ }^{38}$. $\mathrm{Si}$, como veremos, el pensamiento de Jesús pone in actu exercito su ser, este se co-instituye también en la relación con los hombres. En esta relación su pensamiento aprende qué significa ser lealmente hombre (véase lo que dice del centurión: Lc 7, 6-9); se regocija aprendiendo de qué modo el Padre se hace conocer por los hombres (L IO, 2I); aprende terrenalmente el significado de la amistad (llora por su amigo Lázaro: Jn II, 33). De los mismos pensamientos de los hombres, cristalizados en sus refranes, aprende cómo ellos piensan (“Cuando veis una nube que se levanta en el occidente...": Lc I2, 54). Aprende del viñador que tiene una higuera plantada en su viña la relación terrenal entre ser y tiempo ( $\mathrm{Lc}$ I3, 8-9); aprende de los niños la degeneración patológica de los hombres (Lc 7, 3I-35; Mt II, I6-I9) y de ellos comprende quiénes son los sujetos cívicos del Reino de Dios (Mt I9, I3-I4, passim). De los mismos pecados de los hombres aprende el mal de cuál debía rescatarlos y la esperanza de que aquellos se dejen encontrar y salvar. Estos pecados introducen "un punto de pensamiento, de inquietud" en Jesús, es más, introducen la esperanza, virtud teologal, en él y en el Padre ${ }^{39}$.

Estos son solo algunos ejemplos de cómo Cristo ha aprendido y ha enriquecido su pensamiento de lo que ha visto en los hombres. De hecho, su predicación está llena de menciones a lámparas, calabazas, celemines, dracmas, viudas, publicanos, pastores, porquerizos, vaqueros, granjeros, viñateros, aparceros, pequeños cultivadores, cosechadores, samaritanos, centuriones, enfermos, posaderos, es decir, de todo lo que había visto en sus treinta y tres años.

Por otro lado, su pensamiento acontece com-poniéndolo con los

I2, a. 3. Suma de Teología. BAC: Madrid, I994, p. I58.

38 O. GONZÁLEZ DE CARDEDAL. Cristología..., p. 70.

39 C. PEGUY. Le Porche du Mystère de la deuxième vertu, en Euvres poétiques et dramatiques. Gallimard: Paris 2014, pp. 708-709. 
hombres, ya que él no quiere imponerse, sino proponer terrenalmente la misma alianza y acontecer de pensamiento que vive intratrinitaria y terrenalmente con su Padre. Esto implica que el trabajo de encarnación del Logos no es distinto del método, es decir, de la lógica con que Cristo pensó cómo cumplir la redención de los hombres. De hecho, su método ha consistido, ante todo, en engendrar partners-socios-aliados, en fin, amigos (Lc I2, 4) a los que ha dicho todo lo que ha oído de su Padre (Jn I5, I5). En esto Cristo sigue el pensamiento de su Padre, el de la primera Alianza, que hablaba a Moisés "como un hombre habla con su amigo" (Ex 33, II). Esto significa que a Cristo no le ha interesado de ninguna manera tener esclavos sumisos al saber superior e inimputable de un Dios indefinido, sino que ha querido reconstituirlos como hijos y co-herederos (Rom 8, I7), capaces de pensar cómo hacer fructificar la herencia de la oeconomia salutis. Por ello, san Pablo podrá definir a los hombres que Cristo elige como "co-operadores de Dios" (I Co 3, I9) ${ }^{40}$.

\section{I.5. Un apéndice: el cuerpo-pensamiento de Cristo}

En este punto, aunque de modo muy sintético podemos decir algo sobre el cuerpo de Cristo ${ }^{41}$.

Ya hemos aludido en la introducción del riesgo de docetismo si se llegara a afirmar que el cuerpo de Cristo es aparente-irreal, es decir, que

4 o Se ha comentado así esta afirmación paulina: "Somos co-operadores (co-ouvriers) de Dios. Es una máxima magnífica. Allí donde viene menos la figura de un amo (maître), se pone aquella, conjunta, del obrero (ouvrier) y de la igualdad. Toda igualdad es aquella de la co-pertenencia a una obra": A. BADIOU. Saint Paul. La fondation de l'universalisme. Presses Universitaires de France: Paris, 1997, pp. 63-64. Traducción nuestra.

4I Cf. entre otros: F. GARCÍA-MARTÍNEZ, "Me has dado un cuerpo...Jesucristo y el cuerpo humano". Ciencia Tomista. I48/468 (202I), pp. 47-79. En referencia al hombre se ha escrito de modo pertinente, evitando un dualismo nefasto entre cuerpo y pensamiento, que "según la fe cristiana, el lugar para comprender al hombre no es el análisis de sus componentes, alma-cuerpo, por los cuales él pertenecería a mundos diversos, hasta opuestos (sensible-inteligible / materia-espíritu), sino la relación de la cual es hecho partícipe por Dios y para la cual lo capacita": G. LAITI. "Il corpo tra interiorità e relazione", en: D. ALBARELLO - A. COZZI - G. LAITI - M. RECALCATI. Il corpo nell'esperienza cristiana. Glossa: Milano, 20II, p. 25. Cursivas nuestras. Por otro lado, se ha escrito, siempre en referencia al hombre: "La relación primaria [del hombre con Dios] no es aquella entre dos partes del hombre, sino aquella entre el hombre y Dios": G. BONACCORSO. Il corpo di Dio. Vita e senso della vita. Cittadella: Assisi, 2006, p. 49. Está claro que estas afirmaciones de la antropología cristiana se fundamentan en una adecuada concepción del cuerpo-pensamiento de Cristo: en Jesús no hay una esquizofrenia-dualismo entre cuerpo y pensamiento, sino que su cuerpo es cuerpo cuya ley de movimiento es el pensamiento compuesto con el Padre (y con los hombres). Por otro lado, la relación de Cristo con su Padre no está esquizofrénicamente dividida como si él viviera esta relación, por un lado, con su cuerpo y, por otro lado, con su pensamiento. Su cuerpo es, propiamente, el método con el cual él piensa con su Padre (y con los hombres) cómo encarnarse y cómo redimir a "los suyos" (Jn I, II). Aunque no enfaticen esta lógica que proponemos, son valiosas las siguientes obras que abordan este tema: A. GESCHÉ - P. SCOLAS (eds.). Le corps chemin de Dieu, Cerf-Université Catholique de Louvain: Paris, 2005; L. MANICARDI. Il corpo. Via di Dio verso l'uomo, via dell'uomo verso Dio. Qiqajon: Magnano, 2005. 
no sería realmente el cuerpo de un pensamiento ${ }^{42}$. Esta herejía llega, por tanto, a concebir un cuerpo genérico e indistinto, causado y no engendrado por el Logos, no com-puesto por la persona del Hijo. Por otro lado, dado que para el docetismo el pensamiento de Cristo no tiene cuerpo de un vere homo judceus, su pensamiento termina siendo abstracto, supra temporal, religiosamente ecuménico, el de un Dios indistinto ${ }^{43}$. De tal modo, se vuelve un pensamiento que no mueve cuerpo alguno, terminando por ser un pensamiento abstracto e indiferenciado, el de una theologia perennis ahistórica que es desde siempre y no acontece jamás.

Ahora bien, el cuerpo de Cristo no fue causado (factus) por el Logos, sino que fue engendrado (genitus) a través de la com-posición de pensamiento entre el Verbo y la razón del hombre Jesús. Su cuerpo acontece a través de la elaboración in actu exercito del pensamiento de encarnarse y salvar a los hombres. De este modo, el cuerpo de Jesús no es meramente biológico-natural-físico, sino un cuerpo pensante y pensado, el cuerpo que tiene como ley de su movimiento la complacencia del Logos en hacerse hombre y redimir. Propiamente, el cuerpo de Cristo es el "templo de su cuerpo" (Jn 2, 2I), un cuerpo bio-lógico, meta-físico, sobre-natural ${ }^{44}$, el del Hijo unigénito, bien distinto de los ídolos cuya realidad material es meramente natural, sin movimiento (Sal II5; Sal I35). De hecho, el cuerpo de Cristo se mueve por el pensamiento com-puesto y com-placido con el Padre y con su carne humana en que se hace hombre y redime. El cuerpo de Cristo es la conclusión y satisfacción de un pensamiento fruto de una alianza. En este sentido, Pablo puede escribir que en Cristo "habita toda la plenitud de la divinidad corporalmente" $(\mathrm{Col} \mathrm{2,9)}$.

\section{Las dimensiones del acontecer del pensamiento de Cristo}

Las reglas de método con que Cristo ha pensado cumplir su encarnación y redención, se han hecho evidentes para los hombres, son su testimonio dado frente a ellos y estos pueden reconocer dos dimensiones que identifican el acontecer de su pensamiento: su autoridad y su imputabilidad.

42 A. MOLTENI. "El docetismo gnóstico y el cuerpo-pensamiento real de Cristo", en D. MUNDACA (dir.) Un espacio a las aventuras del cuerpo. Estudios interdisciplinarios sobre la historicidad del cuerpo. UdeC: Concepción, 2015, pp. 77-96.

43 Estamos distantes de la lectura religiosa del judío piadoso Jesús competente solo sobre la relación especial con Dios como la que hace G. VERMES. La religión de Jesús el Judío. AnayaMario Muchnik: Madrid, 1996. Por otro lado, no nos parece pertinente decir que Cristo tenía "un sentimiento de intimidad personal con la deidad": E. P. SANDERS. La figura histórica de Jesús. Verbo divino: Navarra, 2000, p. 262. Cursivas nuestras.

44 En Cristo, para usar términos cartesianos, la res cogitans coincide con la res extensa. 


\section{I. La autoridad de su pensamiento}

La ascensión-remontada hecha por Cristo del pensamiento de su Padre que es el de la Primera Alianza y, al mismo tiempo, su pensamiento intratrinitario, el del Logos compuesto con su carne humana y con los hombres, co-instituye en Cristo la autoridad de su pensamiento propio: "Yo soy el que doy testimonio de mí mismo" (Jn 8, I8).

En los Evangelios se relata que todos quedaban sorprendidos de la autoridad del pensamiento de Cristo: "La gente quedó maravillada de su enseñanza, porque Jesús hablaba como quien tiene autoridad" (Mc I, 22); "Les enseñaba como quien tiene autoridad" $(\mathrm{Mt} 7,29)$ "¿Con qué autoridad haces estas cosas? ¿y quién te dio esta autoridad?” (Mt 2I:23).

Esta autoridad competente es bien distinta de cualquier autoritarismo propio de un saber y estatus que abusa de sus privilegios, pues Cristo, en su kénosis (Fil 2, 6-8) no se ha amparado detrás de su saber divino. Tampoco su autoridad deriva de una repetición sumisa o que se resguarda detrás de un mandato recibido como si fuera un imperativo categórico.

Ante todo, ella es, más bien, el fruto del trabajo que Cristo hace sobre la herencia legítima de pensamiento que lo co-instituye como Logos en la relación con su Padre. Cristo tiene la autoridad del Hijo unigénito (Jn 3, I8) y, por ello, de heredero del pensamiento del Padre. Ahora bien, Cristo se muestra como Hijo y heredero en cuanto trabaja la herencia de pensamiento económico de su Padre: "Mi Padre trabaja hasta ahora y yo también trabajo" (Jn. 5, I7). Si no lo hiciera, no podría ser reconocido como Hijo y heredero legítimo del patrimonio de su Padre. De hecho, el Padre le ha confiado todo y él es legítimo heredero universal: "El Padre ama al Hijo y ha puesto todo en su mano" (Jn 3, 35); "Todo me ha sido entregado por mi Padre" (Mt II, 27; cf. Lc IO, 22).

Es más, el Padre le ha dispuesto un Reino (Lc 22, 28; Ap, 22, 28) para que fructifique en vida eterna, es decir, sin pérdida, como corresponde a una real oeconomia salutis, es decir, sana y provechosa: "Según el poder que le has dado sobre toda carne, dé también vida eterna a todos los que tú le has dado" (Jn I7, 2). En este sentido, la autoridad de pensamiento de Cristo se demuestra justamente por el trabajo de su herencia, pues si no la trabajara, no podría ser reconocido como Hijo y, al mismo tiempo, tampoco el Padre podría ser reconocido como tal. 
A este respecto, su pensamiento de Hijo y heredero legítimo, es su doctrina y pensamiento propios y, al mismo tiempo, son las de su Padre: "Mi doctrina [pensamiento] no es mía, sino de quien me ha enviado" (Jn 7, I6). Esta afirmación describe perfectamente la autoridad de pensamiento de Cristo: al contrario del siervo que ha enterrado su talento (Mt 25, 25), su autoridad es la del trabajo fructuoso del talento del pensamiento com-puesto con su Padre desde su primera edad (Lc 2, 49). La encarnación y redención de los hombres son los dos frutos del trabajo de pensamiento del Hijo-heredero hecho hombre que "vino entre los suyos" (Jn I, II), entre los hombres y en su pueblo hebreo a retomar posesión de su herencia legítima haciéndola fructificar.

En segundo lugar, esta autoridad de Cristo, de su pensamiento, se sustenta en su competencia de lo que significa ser hombre: él es experto en humanidad ${ }^{45}$. Hacerse hombre es un provecho para él, una ganancia, de otro modo habría quedado siendo "solo Dios" ${ }^{46}$, no habría añadido a su ser Dios la experiencia provechosa de ser hombre ${ }^{47}$. Su trabajo de encarnación redentora, cumplido en sus ministerios tanto privados como públicos, testimonia su placer de ser hombre. Este placer confirma el pensamiento hebreo de la Antigua Alianza según el cual Dios se habría regocijado de ser hombre: Deliciae meae esse cum filiis hominum (Pr. 8 , 3I). No comprender esto ha implicado el nacimiento de una serie de clichés cristológicos según los cuales la encarnación sería un escándalo, un sacrificio y una oblación desinteresada-amorosa, la de un Dios que se mezcla con lo opuesto a él, con el hombre, con el objetivo de ser solo un complemento para llenar lo que a este hombre le falta ${ }^{48}$. Si el Padre ha mostrado su gusto y amor por el hombre en la encarnación de su Hijo ("Tanto amó Dios al mundo que dio su Hijo único": Jn 3, I6) ${ }^{49}$, por otro lado, Cristo ha mostrado su deseo y placer de ser hombre, ha reconocido que ser hombre y estar con los hombres era un provecho para él, que ser hombre era su deseo ("Permaneced en mi amor-in dilectione mea": Jn I5,

45 La famosa afirmación de Pablo VI a la ONU en I965 -la Iglesia como experta en humanidad-, tiene fundamento cristo-lógico: Cristo es experto en qué significa ser hombre.

46 Es lo que afirma C. PÉGUY. Dialogue de l'histoire et de l'âme charnelle..., p. 726.

47 Véase el interesante ensayo de J. MALÈGUE, Ce que le Christ ajoute a Dieu (Lo que Cristo añade a Dios) contenido en su obra Pénombres: glanes et approches théologiques. Spes: Paris, 1939, pp. II-74. 48 Para el justo rechazo de un Dios hecho hombre entendido como un complemento-tapagujeros a lo que supuestamente le faltaría al hombre, véase D. BONHOEFFER. Resistencia y sumisión. Sígueme: Salamanca, 200I, pp. 218; 266; en contra de la necesidad de postular un Deus ex machina que solucionaría lo que el hombre no puede, ver en la misma obra las páginas 198; 239; 253. Se ha hablado de la lógica de Cristo al encarnarse y al redimir, como de una "lógica de sobreabundancia", ya que "Jesucristo mismo en su persona es el «mucho más» de Dios": P. RICOEUR. La logica di Gesù. Qiqajon-Comunitá di Bose: Magnano, 2009, pp. 30; 77.

49 Se ha escrito de modo pertinente que "Dios ha creado el mundo para poder hacerse hombre". J. RATZINGER. Creazione e peccato. Paoline: Cinisello Balsamo, I986, p. 28. 
9), lejos de cualquier desprecio de la carne en la que se hacía hombre. En este sentido, por ejemplo, su resurrección no debe ser considerada solo como una mecánica operación divina, sino como el fruto del pensamiento de Cristo que pensó como conveniente para él retomar su cuerpo. Lo que además es confirmado en su Ascensión, en cuanto demuestra que consideró también conveniente permanecer in saecula saeculorum como hombre ${ }^{50}$.

Esta competencia y autoridad de pensamiento es la que le permite constituirse, con su presencia com-puesta con los hombres, como juicio universal: "El Padre no juzga a nadie, sino que todo juicio lo ha entregado al Hijo" (Jn 5, 22), pues el Padre "le ha dado poder para juzgar" (Jn 5, 27). El poder de Cristo, lejos de cualquier autoritarismo, consiste precisamente en su autoridad de pensamiento com-puesta con su Padre ${ }^{51}$ y, en su carne, con los hombres. A este propósito, su poder y autoridad de pensamiento se manifiesta sobre todo en el hecho de que Cristo se autoriza por sí solo sin necesidad de mandatos, ya sea familiares (Lc 2, 49), ni epistemológicamente superiores ("No es que yo busque testimonio de un hombre": Jn 5, 34) o estatales ("No tendrías contra mí ningún poder, si no se te hubiera dado de arriba", dice a Pilato: Jn I9, II). Autorizarse por sí solo y componer su competencia con otros (el Padre y los hombres), no son términos contradictorios: significa más bien que Cristo toma la iniciativa para componer y emprender un acontecimiento de pensamiento com-puesto.

En este sentido, Cristo es el hombre realmente modernus, en su sentido etimológico, el hombre realmente presente en sus actos, capaz de un pensamiento sui iuris que pone en acto, eterna y temporalmente, la elaboración de la herencia del pensamiento del Padre. Se podría decir que es el hombre moderno que había soñado vanamente Kant ${ }^{52}$. Por ello, Cristo, con su poder y autoridad de pensamiento propio, se pro-pone en el mundo como un sujeto primum ius, es decir, fuente del derecho, frente al cual el Poder estatal es solo secundario ("Dad al Cesar...”).

50 La expresión de S. FREUD: "Definimos el amar como la relación del yo con sus fuentes de placer" (S. FREUD. "Pulsiones y destinos de pulsión" en Obras completas XIV. Amarrortu: Buenos Aires, 1992, p. 130), puede ser perfectamente utilizada para la lógica con que Cristo ha realizado su encarnación: ha amado su humanidad, en la que se hacía hombre, y a los hombres como fuentes de su placer-provecho, lejos de una oblación desinteresada-kantiana.

5I Si por un lado se ha escrito de la autoridad que es "en sentido estricto no mediada", por otro lado, esta no se debe a una genérica "relación inmediata con Dios", así como afirma E. P. SANDERS. La figura histórica de Jesús..., p. 262.

52 "La Ilustración es la liberación del hombre de su auto-culpable minoría de edad": I. KANT. Filosofía de la historia. Qué es la ilustración. Terramar: La Plata, 2004, p. 33. 
Finalmente, se puede decir que la autoridad de competencia del pensamiento de Cristo es sana ${ }^{53}$. El suyo es un pensamiento inocente (Pilato afirma: "Ningún delito encuentro en él": Jn I9, 6); no es ingenuo ("Sed prudentes como las serpientes, y sencillos como palomas": Mt IO, I6); no es contradictorio (parricida) con el pensamiento de su Padre (“ ¿No habéis leído que el Creador desde el comienzo «los hizo varón y hembra?": Mt I9, 4); no es paradójico ni confuso ("Sea vuestro lenguaje: «Sí, sí»; «no, no»": Mt 5, 37); está satisfecho de su relación de pensamiento con el Padre ("Este es mi Hijo amado, en quien me complazco": Mt 3, I7; I7, 5) y de su trabajo de encarnación y redención: Consummatus est, todo está bien cumplido (Jn I9, 30). Por todo ello, se debe decir que Cristo tiene razón, es decir, una lógica sana que le permite pro-ponerse como amigo del pensamiento de cualquier hombre y lo dispone para co-instituir una societas-civitas con ellos. Como escribía Péguy, "no vamos a buscar nuestros santos a la Salpètrière [el manicomio de París], ni, sobretodo, a Jesús" ${ }^{4}$.

\subsection{Un pensamiento-ser imputable}

La segunda dimensión del pensamiento de Cristo es su imputabilidad frente a su Padre y los hombres.

Hay que aclarar de antemano que entendemos aquí laimputabilidad como capacidad de ser juzgado a través de un juicio, no necesariamente en sentido penal, como demostración de culpabilidad. En este sentido, ser imputable, para Cristo, significa su capacidad de ser conocido y juzgado por sus actos (pensamientos, palabras, obras) como sujeto sui iuris, no por una esencia presupuesta.

Ante todo, a la pregunta de Cristo: "Vosotros, ¿quién decís que soy yo?” (Mt I6, I5), se podría responder que es el Hijo, el Logos-Pensamiento, quien terrenalmente se hace imputable frente a su Padre y a los hombres. La revelación que es Jesús, del Padre y del mismo Hijo, es sinónimo de

\footnotetext{
53 Pensamos que es interesante y pertinente, pues no la considera como pre-supuesta, la cuestión puesta por el título del libro muy poco conocido de: A. SCHWEITZER. Die psychiatrische beurteilung Jesu. Verlag Von J.C.B. Mohr: Tubingen, 1913. La única traducción que hemos encontrado es la italiana y se encuentra en http://www.sicedizioni.it/. [consulta: 202I-OI-O7]. En el prefacio, Schweitzer dice que quiere retomar la hipótesis introducida por D. F. Strauss que describe la figura de Jesús en los términos clásicos de la psicopatología. En el meollo de su obra trata de las distintas opiniones siquiátricas de varios autores de inicio del siglo XX que ubican el pensamiento de Cristo dentro de distintas psicopatologías. Disponible en: https://archive.org/ details/diepsychiatrischooooschw/page/44/mode/2up.

54 C. PÉGUY. Un nouveau théologien, en Euvres en prose complètes III..., p. 455.
} 
imputabilidad55.Es más, la Revelación es el método con el cual la Trinidad se hace imputable en la historia. En este sentido, se puede decir que la naturaleza ontológica de Cristo es la de un sujeto jurídico imputable económicamente por sus actos-frutos, ya que su dogma gnoseológico vale también para él: arbor ex fructu cognoscitur (Lc 6, 44) ${ }^{56}$. El ser de Cristo no consiste en una ontología ya hecha, estática, sino que es, por un lado, la continuación terrenal de las relaciones intratrinitarias que son, lato sensu, constituidas jurídico-económicamente. Las tres Personas se co-instituyen como recíprocamente imputables económicamente en sus relaciones en las que com-ponen su ser. El mismo Padre es hecho imputable a través del trabajo de encarnación-redención del Hijo: "El que no honra al Hijo, no honra al Padre que lo ha enviado" (Jn 5, 23). Cristo mismo no necesita de otro testimonio, él testimonia por sí mismo, pues en su trabajo de encarnación-redención se hace imputable el mismo pensamiento de su Padre que lo ha enviado y en el que él permanece: "Yo soy el que doy testimonio de mí mismo, y el Padre que me envió da testimonio de mí" (Jn 8, I8). Lo que significa que Cristo testimonia-revela al Padre, al mismo tiempo que el Padre se hace imputable, se revela justamente enviando a su Hijo.

En segundo lugar, su ser es el de un vere homo. Cristo no quiere ser imputable solo frente a su Padre, sino frente a los hombres, aceptando la comparación leal con ellos, sin recurrir a ayudas extraordinarias, divinas. De hecho, la encarnación y redención no han sido pensadas ni cumplidas por él con una lógica deductiva ni mecanicista, pues Cristo no ha deducido estas dos operaciones de su naturaleza divina, de sus atributos ontológicos. Para realizar su encarnación redentora, no se ha servido de ayudas sobrenaturales especiales, pues Jesús ha sido lealmente "hombre enviado a los hombres" 57 . Para este trabajo valen las expresiones de san Pablo: Cristo debe ponerse entre los hombres "como obrero que no tiene por qué avergonzarse" (2 Tim 2, I5), pues debe combatir su batalla terrenal con medio legítimos, no fraudulentos: "Quien combate en una batalla no recibe la corona si no ha competido de modo legítimo" (2 Tm

55 Poner el énfasis sobre la imputabilidad jurídico-económica de la revelación, así como es presentada en la Escritura, ayuda a des-helenizar el pensamiento cristiano, puesto que "se ha difundido ampliamente la opinión de que la revelación cristiana está íntimamente ligada a la filosofía griega". I. DE LA POTTERIE. La verdad de Jesús..., p. 8. Esta filosofía es hija de Parménides para quien el "ser es", está ya hecho, es inmóvil. Al igual que el Motor inmóvil aristotélico, la realidad no necesita trabajar para hacerse imputable en su ser.

56 "Este Verbo, que estaba oculto para los hombres, se manifestó según la Economía del árbol": IRENEO. Contra los herejes..., p. 515. Está claro que aquí Ireneo se refiere al árbol de la cruz. Sin embargo, nos parece que no excluye nuestra lectura, que el árbol se conoce por los frutos.

57 CONCILIO VATICANO II, Testo latino-italiano: Dei Verbum 4. Dehoniane: Bologna, 1966, p. 497 . 
$2,5)^{58}$

En tercer lugar, su ser es el de un vere homo judoeus: su Padre es el de los Patriarcas que se hace conocer a través de la imputabilidad económica de sus mirabilia, de los beneficios producidos en la historia de Israel. Por ello, Jesús, como hombre judío, puede decir a la samaritana: "Nosotros adoramos lo que conocemos" (Jn 4, 22), pues el Dios de la Alianza se ha hecho cognoscible en cuanto imputable en la historia.

Ahora bien, el dogma epistemológico de Jesús: arbor ex fructu cognoscitur, indica no solo la originalidad del pensamiento de Cristo, sino el método que él ha propuesto para ser conocido, juzgado (imputado). De hecho, si para la ontología griega se conoce algo por el ser que ya es, por su esencia-sustancia precedente, ya hecha y que no necesita de trabajo para ser, es decir, para acontecer como ser, Cristo afirma que no se puede conocer su ser de modo antecedente a sus frutos. Su ser se conoce solo in actu exercito, mejor dicho, como esse ut actus imputandi. En esto es fiel al Dios de la primera Alianza que había revelado su ser, es decir, su nombre (Ex 3, I4) y el método para reconocerlo diciendo que era "el Dios de vuestros Padres, el Dios de Abraham, de Isaac, de Jacob" $(\operatorname{Ex} 3$, I5).

Si el ser de Cristo consiste en su imputabilidad, en su esse ut actus imputandi, la lógica de su mismo pensamiento no es ontológica (al modo de la filosofía griega), sino más bien jurídico-económica. Su pensamiento quiere ser imputado-juzgado-conocido (dimensión jurídica) por los frutos, por los beneficios que él produce (dimensión económica). Este método está en línea tanto con su pensamiento co-instituido en las relaciones intratrinitarias como con su ser vere homo judoeus.

De este pensamiento debe dar cuenta frente al Padre y frente a los hombres. De hecho, se puede decir que Cristo quiere ser conocidojuzgado-imputado por sus frutos: "Muchas buenas obras os he mostrado de mi Padre; ¿por cuál de ellas me apedreáis?" (Jn Io, 32). El proceso a Jesús no está solo al final de su vida, sino que es desde su infancia (desde el odio de Herodes) y lo acompaña, sobre todo, en su ministerio público, ya que Cristo pone y pro-pone públicamente su ser en cada uno de los actos con los que piensa su encarnación y redención de los hombres.

A este propósito, y esta es una importante inferencia, se puede decir

58 Traducción nuestra del texto de la Vulgata: Qui certat in agone, non coronatur nisi legitime certaverit. 
que su ser es puesto por medio de su pensamiento, es decir, por cómo piensa cumplir su encarnación redentora. Por tanto, su ser no puede ser distinto de la lógica con que piensa encarnarse y redimir a los hombres y el pensamiento de cómo cumplir estas dos operaciones co-instituye su ser, lo pone en acto como esse ut actus imputandi.

\section{Conclusiones y sugerencias}

Aunque de modo sintético, nos parece haber mostrado los núcleos en que consiste el acontecer del pensamiento de Cristo. Hemos desarrollado la afirmación paulina ( $\mathrm{Co} 2, \mathrm{I} 6$ ) considerando que no se puede hablar de este pensamiento sin reconocerlo en su acontecer ya sea intratrinitario, en la relación del Logos con su carne de hombre y de hombre judío, en la relación con los hombres. En este sentido, hemos llegado a la conclusión de que no se puede entender el ser de Cristo sin reconocerlo como puesto terrenalmente por su pensamiento. En este ponerse de su pensamiento en un cuerpo de hombre consiste el acontecer de su autoridad e imputabilidad que tiene como norma fundamental, en base a la cual es juzgada-imputada, la ley de la alianza com-puesta con el Padre, con su cuerpo pensante y con los mismos hombres. El ser de Cristo se revela en la imputabilidad económica (frente al Padre y los hombres) con la que ha pensado hacerse carne y redimir a los hombres: su ser es un esse ut actus imputandi. Lo que significa que su ser es, propiamente, acontecer, siempre imprevisto e imprevisible, del modo en cómo él piensa públicamente, en el ágora de los pensamientos, su encarnación redentora.

Este reconocimiento del pensamiento de Cristo que pone terrenalmente su ser, pensamos que ofrece varias sugerencias que pueden servir para solucionar algunas temáticas referentes al modo de entender y re-conocer a Cristo. Entre ellas, señalamos solo algunas de modo sintético.

En primer lugar, permitiría reconocer en qué consiste, para Cristo, su ser vere Deus. De hecho, su pensamiento es com-puesto y acontece en la relación con su Padre que es el de la Alianza con Abraham e Israel, de ningún modo con un Dios genéricamente religioso, indistinto. Al mismo tiempo, facilitaría el reconocimiento de su ser vere homo, hombre que es tal en cuanto ha pensado cómo cumplir su encarnación y redención, operaciones realizadas no como hombre indistinto, sino como vere homo judoeus.

En segundo lugar, facilitaría mostrar que la encarnación no puede 
ser disociada de la redención, sino que ambas son un acto unitario. Así como Cristo piensa su encarnación depende el modo-método en cómo él piensa cumplir la redención de los hombres. En esto seguimos lo que afirmaba Péguy: "La encarnación se explica (s’eclaire) por la redención" 59 , aseveración que puede implicar desarrollos muy significativos. Por otro lado, permitiría entender la encarnación y redención de Cristo no como efectos de un mecanismo divino presupuesto que causaría estas dos operaciones, sino como el fruto de su pensamiento que debió elaborarlas y cumplirlas terrenalmente, de modo unitario. Se solucionaría, de este modo, la división-separación de los antiguos manuales entre un De Verbo incarnato y un De Christo redemptore ${ }^{60}$, separación que es una tentación siempre presente en el ámbito de la fe cristiana.

En tercer lugar, estos planteamientos podrían entregar los materiales para una elaboración y solución del mal puesto problema de la relación entre lo que se ha llamado (con términos discutibles) "el Jesús de la historia" y "el Cristo de la fe". Por un lado, se puede decir que su historicidad es evidente, ante todo, en su pensamiento que remonta la lógica hebrea-veterotestamentaria. Por otro lado, es evidente porque su pensamiento-cuerpo se ha revelado y hecho imputable en el ágora pública, ha sido discutido, aceptado o removido. Por otro lado, se evidenciaría que el así llamado "Cristo de la fe" es el mismo Jesús que ha pensado cómo encarnarse y redimir a los hombres. La fe no ha inventado ni producido los milagros de Cristo, los contenidos de su predicación, su resurrección-ascensión, pues estos no deben ser considerados como hechos extra-ordinarios (meramente divinos), sino como frutos cotidianos del pensamiento del Logos que ha pensado cómo hacerse lealmente hombre.

En cuarto lugar, estimamos que se puede hablar de Cristo como acontecimiento solo considerando el acontecer in actu exercito de su pensamiento, es decir, el método-camino con que él ha debido pensar cómo cumplir su encarnación y la redención de los hombres. De esto se puede inferir que su ser, su naturaleza propia de acontecimiento, es la de un pensamiento que es engendrado (no causado) por el pensamiento del Padre y que él vuelve a remontar como hombre judío con los hombres. Se podría así hablar de Cristo como acontecimiento solo implicando esta remontada-ascensión. De otra manera, caeríamos en un gnosticismo que entiende el acontecimiento de Cristo no como el de

59 C. PÉGUY. Le mystère de la charité de Jeanne d'Arc, en CEuvres poétiques et dramatiques..., p. 464. 6o Véase M. SERENTHÀ, Gesù Cristo. Ieri, oggi e sempre. Saggio di cristologia. Elle Di Ci: Torino, I982, pp. 289-29I. 
un sujeto que asciende desde su humanidad específicamente hebrea, sino que "desciende gnósticamente, como cayendo de los cielos" ${ }^{\text {. }}$. No se podría, por tanto, hablar del acontecimiento de Cristo sin identificarloreconocerlo en el acontecer de su pensamiento que asciende y remonta tanto la lógica intratrinitaria en su encarnación en cuanto vere homo judous como, al mismo tiempo, el pensamiento de los hombres que él encuentra. Estimamos que vincular a Cristo con el acontecer de su pensamiento permite pensarlo de modo adecuado como acontecimiento ${ }^{62}$.

Finalmente, vincular a Cristo con el acontecer de su pensamiento implicaría proponer al juicio de los hombres no cristianos la posibilidad de averiguar la salud de este pensamiento, es decir, los pondría en condición de imputarlo-juzgarlo por sus contenidos lógicos y cívicos que no contradicen ni la dinámica racional-razonable, ni la constitución de una civitas terrenal sana. Por otro lado, la elaboración de la herencia del pensamiento de Cristo vendría a constituir para los cristianos el acontecer del pensamiento de la fe, una fides cogitata ${ }^{63}$ que, al igual que el acontecer del pensamiento de Cristo que es tal en cuanto asciende-remonta el pensamiento del Padre como vere homo judoeus ${ }^{64}$, acontece solo en esta ascensión crítica, es decir, en una ascensión pensada del pensamiento de su Fundador.

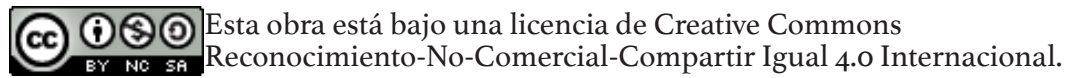

\footnotetext{
6I Retomamos aquí la afirmación de H.U. von Balthasar que ya hemos señalado.

62 Véase las valiosas observaciones de Ratzinger sobre el acontecimiento de Cristo: Illud quod Deus homo fieri voluit et incarnatus est, praecedit «est» ontologicum confessionis calcedonensis, eiusque fundamentum historicum, temporale est; in illo «est» semper istud "fieri» et sic historia Dei cum hominibius praesens manet ("El hecho de que Dios quiso hacerse hombre y se encarnó precede al «es» ontológico de la confesión de Calcedonia y es su fundamento histórico, temporal; en aquél «es», siempre permanece presente este "acontecer»") J. RATZINGER. "De relatione inter conceptum historiae salutis et quaestionem eschatologicam"en D. SHÖNMETZER (dir.) Acta congressus internationalis de theologica concilii Vaticani II. Editrice Vaticana: Roma, I969, pp. 484-489. Cursivas nuestras. Afirmaciones que son propuestas de nuevo en modo más sintético en J. RATZINGER. Teología e historia..., pp. 56-57. Lo que hemos expuesto en nuestro estudio no se contrapone a lo afirmado por Ratzinger, sino que lo suplementa. Ambos desarrollos podrían enriquecer el énfasis dado en la filosofía e historiografía moderna al "acontecimiento": véase el estudio sintético de F. DOSSE. Renaissance de l'événement. Un défi pour l'historien: entre sphinx et pheénix. Presses Universitaires de France: Paris, 2010.

63 AGUSTÍN. "De la predestinación de los Santos II", 5 en Obras de san Agustín, tomo VI. BAC: Madrid, I956, p. 484.

64 De aquí la importancia para la fe cristiana de que se haga memoria en el Primer Canon de la Misa del sacrifícium patriárchœe nostri Ábrahœe que, por ello, es nuestro padre en la fe y de la retoma hecha por Benedicto XVI de la afirmación de Pío XI en 1938: "Espiritualmente, nosotros somos semitas". BENEDICTO XVI. Encuentro con la delegación judía. Discurso del Santo Padre Benedicto XVI. París, I2 de septiembre de 2008. [consulta: 07-OI-202I]. Disponible en: https://www.vatican. $\mathrm{va} /$ content/benedict-xvi/es/speeches/2008/september/documents/hf ben-xvi_spe 20080912 parigi-juive.html.
} 